University of Nebraska - Lincoln

DigitalCommons@University of Nebraska - Lincoln

USDA National Wildlife Research Center - Staff Publications
U.S. Department of Agriculture: Animal and Plant Health Inspection Service

May 2005

\title{
Parasitized and non-parasitized prey selectivity by an insectivorous bird
}

\author{
Gregory A. Jones \\ University of Florida, greg.a.jones@sfcc.edu \\ Kathryn E. Sieving \\ University of Florida \\ Michael L. Avery \\ USDA/APHIS/WS National Wildlife Research Center, michael.I.avery@aphis.usda.gov \\ Robert L. Meagher \\ USDA-ARS, Center for Medical, Agricultural and Veterinary Entomology
}

Follow this and additional works at: https://digitalcommons.unl.edu/icwdm_usdanwrc

Part of the Environmental Sciences Commons

Jones, Gregory A.; Sieving, Kathryn E.; Avery, Michael L.; and Meagher, Robert L., "Parasitized and nonparasitized prey selectivity by an insectivorous bird" (2005). USDA National Wildlife Research CenterStaff Publications. 6.

https://digitalcommons.unl.edu/icwdm_usdanwrc/6

This Article is brought to you for free and open access by the U.S. Department of Agriculture: Animal and Plant Health Inspection Service at DigitalCommons@University of Nebraska - Lincoln. It has been accepted for inclusion in USDA National Wildlife Research Center - Staff Publications by an authorized administrator of DigitalCommons@University of Nebraska - Lincoln. 


\title{
Short communication \\ Parasitized and non-parasitized prey selectivity by an insectivorous bird
}

\author{
Gregory A. Jones ${ }^{\mathrm{a}, *}$, Kathryn E. Sieving ${ }^{\mathrm{a}}$, Michael L. Avery ${ }^{\mathrm{b}}$, Robert L. Meagher ${ }^{\mathrm{c}}$ \\ ${ }^{a}$ Department of Wildife Ecology and Conservation, University of Florida, 110 Newins-Ziegler Hall, Gainesville, FL 32611-0430, USA \\ ${ }^{\mathrm{b}}$ USDA National Wildlife Research Center's Florida Field Station, Gainesville, FL 32641-6033, USA \\ ${ }^{\mathrm{c}} U S D A-A R S$, Center for Medical, Agricultural and Veterinary Entomology (CMAVE), Gainesville, FL 32608, USA
}

Received 26 March 2004; received in revised form 29 June 2004; accepted 1 July 2004

\begin{abstract}
The identification and conservation of naturally occurring enemies of crop pests is an important means of improving biological control in cropping systems. One particularly important potential mechanism whereby birds might stabilize and improve pest control is consumption of individual prey that escape mortality from other agents of biological control. We tested the hypothesis that birds prefer to forage upon non-parasitized fall armyworm (Spodoptera frugiperda J. E. Smith) prey via captive feeding trials, where birds were also offered armyworms parasitized by Euplectrus plathypenae (Howard) larvae. While birds were equally willing to eat both parasitized and non-parasitized armyworm prey of the same body size, they strongly preferred larger non-parasitized prey. This preference continued even as this prey item became less numerous than smaller parasitized worms during feeding trials. Our results suggest that birds may contribute to the biological control of arthropod pests that escape control, become larger in body size and, subsequently, a favored prey item.
\end{abstract}

(C) 2004 Elsevier Ltd. All rights reserved.

Keywords: Biological control; Avian prey selectivity; Insectivorous birds

\section{Introduction}

Over the past 2 decades, field entomologists and agronomists have increasingly recognized that the conservation of natural enemies, via the management of non-cropped habitats and other measures, can be important for successful biological control in agricultural systems (Rosen et al., 1996). However, little work has been done examining the role avian insect predators play in modern cropping systems as natural enemies of pests. One particularly important potential mechanism whereby birds might stabilize and improve pest control is consumption of individual prey that escape mortality from other agents of biological control. In systems, where introduced or native parasitoids are supported via

\footnotetext{
${ }^{*}$ Corresponding author. Fax: + 1-352-392-6984.

E-mail address: greg.a.jones@sfcc.edu (G.A. Jones).
}

provision of critical habitat (e.g., insectary plantings) or through repeated releases onto fields, parasitism rates undergo fluctuations due to parasitoid population lags (Bugg and Picket, 1998). Additionally, some pests may avoid parasitism and continue to cause crop damage. In such systems birds could function to stabilize and maintain sufficient pest mortality rates given their abilities to respond functionally to changes in prey abundance (McFarlane, 1976). While this scenario reasonably explains how birds could effectively improve arthropod pest mortality induced by parasitoids typically employed in biological control regimes (McFarlane, 1976; Kirk et al., 1996), its practicality and economic efficiency have not been assessed for any agroecosystem.

Previous observations have confirmed that many birds occurring in cropped fields of north-central Florida actively forage for and consume caterpillars in 
crop vegetation (Jones et al., 2004). Bruns (1959) stated that birds would be of value as insect predators in a system only if they increase the effectiveness of control by taking insects over and above those that would normally have been destroyed by other agents. Sloan and Simmons (1973) reported that parasitized jack pine budworm (Choristoneura pinus Bechstein) larvae and pupae were unanimously rejected by foraging chipping sparrows (Spizella passerina Bechstein). Similarly, Schlicter (1978) reported that black-capped chickadees (Parus atricapillus Linnaeus) largely avoided foraging upon galls on Canada goldenrod (Solidago canadensis Linnaeus) that had been parasitized by mordellid beetle (Mordellistena unicolor LeConte) larvae to extract gall fly (Eurosta solidaginis Fitch) larvae. Therefore it appears that birds have the ability to distinguish prey that have been damaged or may be compromised by a parasite and avoid such prey.

Fall armyworms [Lepidoptera: Noctuidae, Spodoptera frugiperda (J.E. Smith)] are important pests in vegetable and row crops and are often subjected to biological control using augmentative releases (Johnson and Sprenkel, 1996). In this study we addressed whether birds would consume or avoid armyworms that had been parasitized. In both studies where birds avoided parasitized prey, it was suggested that visual cues were utilized to distinguish between prey types (Sloan and Simmons, 1973; Schlichter, 1978). Therefore, in captive feeding trials, we tested the hypothesis that birds prefer to forage upon non-parasitized armyworm prey when birds were offered prey parasitized by the visible ectoparasitoid Euplectrus plathypenae (Howard) (Hymenoptera: Eulophidae) larvae.

\section{Methods}

\subsection{Research facilities and test species}

We conducted feeding trials with red-winged blackbirds (Agelaius phoeniceus L.) captured in agricultural areas of Alachua County, Florida and housed in an aviary at the USDA National Wildlife Research Center's Florida Field Station, Gainesville, Florida. We chose this species because it commonly occurs in agricultural landscapes and it is known to prey on insect pest populations in crops (Bendell et al., 1981, Dolbeer, 1990). We obtained parasitized and non-parasitized fall armyworms from the USDA-ARS, Center for Medical, Agricultural and Veterinary Entomology (CMAVE), Gainesville, FL. Parasitized armyworm larvae had been exposed to and carried larvae of $E$. plathypenae, a species common in Florida and previously investigated for its biological control value.

\subsection{Paired feeding trials with non-parasitized larvae}

The first set of feeding trials performed with nonparasitized prey tested whether captive birds would feed upon fall armyworms and determined their baseline consumption of this food item (following methods described by Avery et al., 1999). Additionally, since birds have exhibited prey size selectivity when presented a choice (Krebs et al., 1977; Davies, 1977) we assessed whether birds exhibited a feeding preference for different instar sizes of caterpillars. We removed maintenance food (fortified cornmeal) by 07:00 and 1-2 $\mathrm{h}$ later presented each bird with a plastic cup divided into two chambers (right and left sides). In the first tests, 18 birds were twice presented 5 armyworms of equal size in each of the cup's two chambers and allowed birds to feed undisturbed for $0.5 \mathrm{~h}$. We recorded the number, chamber where removed (left or right side of cup), and the time it took for the bird to consume all 10.

In a second set of tests, we presented 12 birds that readily ate armyworms in the first tests 10 larvae of two instar sizes, five large (5th instar, $26.1 \pm 3.0 \mathrm{SD} \mathrm{mm}$, $n=28$ ) and five small (2nd or 3rd instar, $14.5 \pm 2.4 \mathrm{SD} \mathrm{mm}, n=28$ ), presented in the cup's two chambers. Birds were allowed to feed until 5 armyworms were consumed or $0.5 \mathrm{~h}$ had elapsed, whichever occurred first. In order to control for any possible bias of position in the cup, we alternated the position of prey type in the 2 chambers (left side or right side) for each trial. In a total of 20 trials we recorded choice of prey size and order of prey taken each time a bird consumed a larva. In these tests, and all that followed, 12 birds were rotated through the feeding trial protocol. During each set of feeding trials the same bird would not be given a subsequent test presentation until at least $1 \mathrm{~h}$ had passed.

\subsection{Prey recognition trials}

In the prey recognition trials, we offered a choice of parasitized and non-parasitized fall armyworms. The objective of the first 20 trials was to document immediate prey preference and overall preference of individual birds to parasitized and non-parasitized prey of equal size. We removed each bird's maintenance food by 07:00 and 1-2 h later presented each with a plastic cup divided into two chambers, one containing 5 parasitized armyworms the other containing 5 nonparasitized armyworms. Each bird fed undisturbed for $15 \mathrm{~min}$ or until it selected 5 caterpillars. In order to control for any possible bias of position in the cup, we alternated the position of prey type in the 2 chambers (left side or right side) for each trial. We recorded the order and number of each prey item taken. In the first set of these prey recognition-feeding trials (20 trials), birds were presented parasitized and non-parasitized 
armyworms of equal body size. In the second set of prey recognition trials (21 trials), we presented parasitized and non-parasitized armyworms of equal age, but different body size since larvae parasitized by Euplectrus exhibit arrested growth within $24-48 \mathrm{~h}$ from a toxin injected during oviposition (Coudron and Puttler, 1988).

\subsection{Data analysis}

Initial preference for choosing the first prey item from 1 of the 2 cup chambers (right vs. left), size (large vs. small), or parasitized vs. non-parasitized prey was determined in the paired trials using Chi-square tests of the null hypothesis that birds chose from each side of the cup or prey type with equal frequency. Because prey items were not replaced after the bird made a choice during each trial, birds were faced with a different array of prey items after each successive choice. Therefore, in order to reflect the successive choices birds made as they were faced with an ever-changing array of prey items during each trial overall prey preference was determined utilizing a stratified Wilcoxon rank-sum tests of the null hypothesis that birds show no preference for feeding upon the paired prey types. Of the five selections, the first food selected by the bird receives rank 5 , the second rank 4, etc., and the fifth receives rank 1. All ranks assigned to a particular prey type are then summed over the many birds in the trial. A preferred food would receive higher ranks and more ranks than a food that was less preferred. The null hypothesis for the rank sum is derived by assuming that each bird randomly selects its next food item, so that selections are made as though an honest coin (having probability of $1 / 2$ of selecting each of the two foods) is tossed each time a food item is selected by the bird. Thus, each rank is randomly assigned to one of the foods based on an independent coin toss. Violations of this assumption causing one of the foods to receive higher rank totals can then be assessed via a $p$-value computed under this null distribution. A small $p$-value thus indicates a strong preference for one of the two foods (R.H. Randles and M. Capanu, IFAS Statistics, University of Florida, FL, pers. comm.).

\section{Results and discussion}

Tests with non-parasitized larvae found that most birds tested (78\%) would quickly consume the 10 larvae presented to them. Those birds willing to eat armyworms consumed all 10 larvae presented to them within $15 \mathrm{~min}$, regardless of instar size. Since most red-winged blackbirds tested ate fall armyworms and were capable of consuming a number of these prey items in short time periods, similar behavior by insectivorous birds in cropped fields could contribute to armyworm control.
This result supports those of Bendell et al. (1981) that predation by red-winged blackbirds was responsible for lowering overwintering European corn borer [Ostrinia nubilalis (Hübner), Lepidoptera: Pyralidae] populations in standing corn of the following year. Many species occurring in the US are wholly or partly insectivorous (Freemark et al., 1991) and as such have great potential for stabilizing insect populations, including crop pests, thus enhancing plant growth via insectivory. For example, avian predation has been observed to significantly impact grasshopper populations through biomass reduction and reduction of species diversity (Joern, 1986). Modeling this impact, Kirk et al. (1996) estimated that a grasshopper-eating passerine family unit could consume $3.7 \mathrm{~kg}$ of grasshopper biomass, or approximately 149,000 individuals per breeding season. Unfortunately, a few avian species such as red-winged blackbirds can also cause damage to many row crops. This damage can be especially high in fields nearest to their favored roost habitats, wetlands in the case of redwinged blackbirds, where large flocks congregate (Dolbeer, 1990).

Birds showed no initial preference for feeding from a particular chamber (right or left side) of the presentation cup $\left(\chi^{2}=0.05, p>0.05, n=19\right)$. Birds did exhibit a significant initial preference for larger armyworms when presented a size difference in prey $\left(\chi^{2}=28.30, p<0.001\right.$, $n=20$ ). These results support those of Krebs et al. (1977) and Davies (1977) that birds exhibited an overall preference for large prey when both large and small food items were in abundance. Interestingly, in this study birds continued to exhibit a significant overall preference for larger prey even while this prey item became increasingly less numerous than smaller worms in the cup during each trial $\left(W_{o}=230, p<0.001\right.$, $n=20)$.

In prey-recognition trials, birds readily ate both parasitized and non-parasitized prey offered to them. Interestingly, some of the Euplectrus larvae became detached from their host when birds handled the caterpillars and often remained behind in the presentation cup. When the cup was left in the cage, birds often consumed the free Euplectrus larvae. Birds did not exhibit an initial preference between simultaneously presented parasitized and non-parasitized armyworms of the same size $\left(\chi^{2}=1.0, p>0.05, n=20\right)$ nor an overall preference between these prey types in the cup during each trial $\left(W_{0}=139, p=0.69, n=20\right)$. However, birds did exhibit a significant initial preference for larger non-parasitized armyworms versus the smaller parasitized prey of the same age $\left(\chi^{2}=38.44, p<0.001\right.$, $n=21)$. Birds also showed a significant overall preference for the larger non-parasitized prey $\left(W_{0}=248\right.$, $p<0.001, n=21$ ) even as this prey item became increasingly less numerous than smaller parasitized worms during each trial (Fig. 1). 


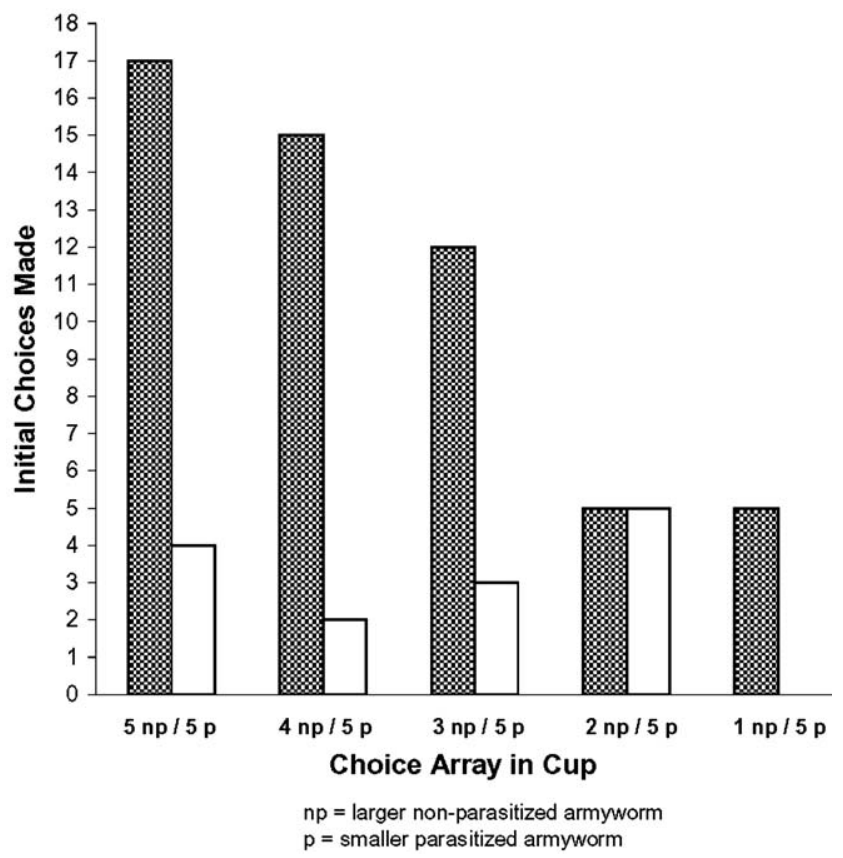

Fig. 1. In the prey recognition trials, we offered red-winged blackbirds (Agelaius phoeniceus $\mathrm{L}$.) a choice of parasitized and non-parasitized fall armyworms [Lepidoptera: Noctuidae, Spodoptera frugiperda (J.E. Smith)] and recorded the order and number of each prey item taken until 5 worms were eaten. In the 21 feeding trials offering simultaneous pairings of larger non-parasitized over the smaller parasitized armyworms, birds exhibited a significant overall preference for the larger non-parasitized prey $\left(W_{o}=248, p<0.001, n=21\right)$. As this prey type became comparatively less numerous during each feeding trial, birds usually choose the largest worm available in the presentation cup first. This was true even in the 5 cases were only one large worm vs. five smaller parasitized worms were remaining in the cup.

While red-winged blackbirds were equally willing to eat parasitized and non-parasitized fall armyworm prey of the same body size, in this study birds showed a strong preference for larger lepidopteran prey. Fall armyworm larvae that have escaped parasitism quickly become larger in body size compared to those parasitized by Euplectrus wasps. Birds overwhelmingly preferred these larger caterpillars when they were given a choice between the 2 prey types subsequently avoiding parasitized prey. Sloan and Simmons (1973) observed that the avoidance of parasitized prey by chipping sparrows appeared to be related to a size difference between parasitized and non-parasitized jack pine budworms. Similar to larvae stung by ovipositing Euplectrus wasps, jack pine budworms that had been parasitized by Apantales fumiferanae Viereck (Hymenoptera: Braconidae) are comparatively small. Since many parasitoids, such as those in the genus Euplectrus, cause a significant reduction in body size, birds preferentially foraging for larger caterpillars could indeed increase overall mortality of these pests in cropping systems when parasitoids are present or released for biocontrol.
In addition to reducing the local caterpillar population parasitism reduces the impact of pests by changing its behavior, once parasitized. Parkman and Shepard (1981) measured the difference in foliage consumption between parasitized (by E. plathypenae) and nonparasitized yellowstriped armyworms (Spodoptera ornithogalli Guenée) and found parasitized larvae consumed significantly less foliage $\left(1.23\right.$ vs. $8.85 \mathrm{~cm}^{2} / \mathrm{d} /$ larvae). Additionally, Coudron et al. (1990) found that in most cases parasitized caterpillars cease to feed altogether due to an arrested growth condition. Therefore, our results suggest that birds may enhance yields by consuming those arthropod pests that escape control as they become larger in body size and subsequently a favored prey item.

This study aids in the determination of the pest control potential avian insect predators have in agroecosystems and increases our understanding of the functional role of insectivorous birds in modern agricultural systems. Information obtained from captive feeding trials can be incorporated into estimates of overall pest regulation potential and sets the stage for future field research to investigate actual arthropod biomass reductions due to foraging by insectivorous birds in cropping systems (i.e. exclosure studies etc.).

\section{Acknowledgments}

The authors thank Kandy Roca, and all of the staff members at the USDA National Wildlife Research Center's Florida Field Station, Gainesville, Florida, for their help in conducting experiments. We also thank Charlie Dillard and all of the staff members at the USDA-ARS Insect Behavior \& Biocontrol Unit, Gainesville, Florida, for their help and provision of experimental materials. We gratefully acknowledge the helpful comments on this manuscript of S. E. Naranjo and two anonymous referees. This is Florida Agricultural Research Station Journal Series R-10342.

\section{References}

Avery, M.L., Humphrey, J.S., Decker, D.G., McGrane, A.P., 1999. Seed color avoidance by captive red-winged blackbirds and boattailed grackles. J. Wildlife Manage. 63, 1003-1008.

Bendell, B.E., Weatherhead, P.J., Stewart, R.K., 1981. The impact of predation by red-winged blackbirds on European corn borer populations. Can. J. Zool. 59, 1535-1538.

Bruns, H., 1959. The economic importance of birds in forests. Bird Study 7, 192-208.

Bugg, R.L., Picket, C.H., 1998. Introduction: enhancing biological control-habitat management to promote natural enemies of agricultural pests. In: Picket, C.H., Bugg, R.L. (Eds.), Enhancing biological control. University of California Press, Berkeley, California, pp. 1-24. 
Coudron, T.A., Puttler, B., 1988. Response of natural and factitious hosts to the ectoparasite Euplectrus plathypenae (Hymenoptera: Eulophidae). Ann. Entomol. Soc. Am. 81, 931-937.

Coudron, T.A., Kelly, T.J., Puttler, B., 1990. Developmental responses of Trichoplusia ni (Lepidoptera: Noctuidae) to parasitism by the ectoparasite Euplectrus plathypenae (Hymenoptera: Eulophidae). Arch. Ins. Biochem. Physiol. 13, 83-94.

Davies, N.B., 1977. Prey selection and social behavior in wagtails (Aves: Motacillidae). J. Anim. Ecol. 46, 37-57.

Dolbeer, R.A., 1990. Ornithology and integrated pest management: red-winged blackbirds Agelaius phoeniceus and corn. Ibis 132, 309-322.

Freemark, K., Dewar, H., Saltman, J., 1991. A literature review of bird use of farmland habitats in the Great Lakes - St. Lawrence Region. Canadian Wildlife Service, Technical Report, Series No. 114.

Joern, A., 1986. Experimental study of avian predation on coexisting grasshopper populations (Orthoptera: Acrididae) in a sandhills grassland. Oikos 46, 243-249.

Johnson, F., Sprenkel, D., 1996. Florida Insect Management Guide. IFAS Publications, University of Florida, Gainesville, FL.

Jones, G.A., Sieving, K.E., Jacobson, J.S., 2004. Avian biodiversity and functional insectivory on North-central Florida farmlands. Cons. Bio., in review.
Kirk, D.A., Evenden, M.D., Mineau, P., 1996. Past and current attempts to evaluate the role of birds as predators of insect pests in temperate agriculture. In: Nolan, Jr., V., Ketterson, E.D. (Eds.), Current Ornithology, vol. 13. Plenum Press, New York, pp. 175-269.

Krebs, J.R., Erichsen, J.T., Webber, M.I., Charnov, E.L., 1977. Optimal prey selection in the Great Tit (Parus major). Ann. Behav. 25, 30-38.

McFarlane, R.W., 1976. Birds as agents of biological control. Biologist 58, 123-140.

Parkman, P., Shepard, M., 1981. Foliage consumption by yellowstriped armyworm larvae after parasitization by Euplectrus plathypenae. Florida Entomologist 64, 192-194.

Rosen, D., Capinera, J.L., Bennett, F.D., 1996. Integrated pest management: an introduction. In: Rosen, D., Bennett, F.D., Capinera, J.L. (Eds.), Pest Management in the Subtropics: Integrated Pest Management - a Florida Perspective. Entomological Society of America, Lanham, MD, pp. 3-10.

Schlichter, L., 1978. Winter predation by black-capped chickadees and downy woodpeckers on inhabitants of the goldenrod ball gall. Can. Fld. Nat. 92, 71-74.

Sloan, N.F., Simmons, G.A., 1973. Foraging behavior of the chipping sparrow in response to high populations of jack pine budworm. Am. Mid. Nat. 90, 210-215. 